\title{
Resistance and hope
}

Marilia Sá Carvalho 1

Luciana Dias de Lima 2

Cláudia Medina Coeli 3

doi: 10.1590/0102-311X00023420

We in Brazil (as in many other places in the world) are experiencing highly unfavorable times for health and science. Yet when we face moments like this, we discover new and renewable energy to resist and act.

We at CSP monitor as closely as possible each new event that impacts health, quickly seeking to collect scientific studies and evidence. The Perspectives and Thematic Section sections thus provide outstanding opportunities for debate on relevant current issues for Collective Health in the Brazilian and international scenarios. From 2013 to February 2020, 179 articles were published in these two sections alone.

Without compiling an exhaustive list (after all, the articles are available in the electronic databases), in recent years they have focused on such hot topics as immigration and refugee populations, health and rights of trans populations, and strides and setbacks in mental health policy. The experience with Social Security reform in Chile and its implications for social protection and health was analyzed to extract lessons for Latin America and Brazil. The environment and its interfaces with health were the object of various articles: the disasters associated with mining activities in Mariana and Brumadinho, the oil spill on the Brazilian coastline, and the release of new pesticides. In particular, primary healthcare was debated in depth, due to its importance for the consolidation of public and universal systems, including Brazil's Unified National Health System (SUS). Based on health as a fundamental and universal human right, the theme was approached through the new concepts and guidelines expressed in the Global Conference held in Astana in 2018, in the medical profession's specificities and dilemmas in various health systems around the world, and in specific dimensions of basic healthcare policy reform under way in Brazil. CSP is a scientific journal, and all these themes have been treated with full respect for the diversity of approaches and focuses in Collective Health.

In 2019, CSP also published three special thematic supplements on subjects as varied as population health, health policies, and health systems: schoolteachers' health in basic education in Brazil; public policy networks, regionalization and health; and the health of indigenous children and adolescents in Latin America.

The empirical articles, essays, and reviews published in CSP are the result of enormous and solid knowledge production in the field. In all fairness, it would be impossible to list
1 Programa de Computação Científica, Fundação Oswaldo Cruz, Rio de Janeiro, Brasil.

2 Escola Nacional de Saúde Pública Sergio Arouca, Fundação Oswaldo Cruz, Rio de Janeiro, Brasil. 3 Instituto de Estudos em Saúde Coletiva, Universidade Federal do Rio de Janeiro, Rio de Janeiro, Brasil. 
every topic addressed in CSP. Innovation and scientific quality are the backbone of the journal's editorial policy, reflecting research in all the areas and disciplines comprising the Collective Health field.

CSP is a common resource in knowledge production in Collective Health, each year expanding its international reach, especially in South-South cooperation, the result of accumulated publishing experience. The body of Associate Editors is responsible for organizing the peer review process and has grown steadily, currently consisting of 39 researchers from a wide variety of areas. New fields of knowledge have been incorporated, such as data science, keeping CSP at the cutting edge of science production. In addition, the meetings of associate editors from related areas have established specific policies for the human sciences, policy, planning, and management 1 , and epidemiology.

The editorial board of CSP recently launched a new work front: science dissemination and public communication. Initially investing in digital media (Twitter: https://twit ter.com/CadernosSP; Facebook: https://www.facebook.com/cadsaudepublica/), a pilot test was conducted with the production of two podcasts (https://m.soundcloud.com/us er-234001232). Acknowledging the need for a professional approach, we obtained financial support to conduct workshops with authors and editors of thematic supplements, professionals in the communications field and representatives from society to develop more specific proposals. The idea is to jointly create products that allow the dissemination of contents from key selected articles. It is high time to confront anti-science 2 . This requires acknowledging and confronting the scientific community's limitations (including those of science journals) through open dialogue with society 3,4.

In late 2019, we the Editors-in-Chief of CSP, concerned with the current situation, decided to send messages of gratitude and hope to our partners, editors and reviewers that have contributed so much to the journal. For reviewers, we prepared an electronic mailing list to send our message. However, the list's configuration allowed individual replies to be sent to everyone rather than only to CSP. We were somewhat embarrassed at first - after all, this is not the most adequate procedure - but in the end we were happy with the feedback from colleagues, which was generally positive.

Yes, said our colleagues: “...we need the replies from others, to realize that we're not alone in the pursuit of physical, mental, economic, and moral public health"; "I'd never received 'Happy New Year' greetings from so many researchers!!! It's fabulous!!"; “...I loved getting each and every one of the messages from this group. It's great to know there are so many of us in the Resistance". After all, editors, authors, and reviewers form a huge community. Sometimes we are authors, other times we are consultants, and we comment on colleagues' articles. The role can change, but in each one we make our indispensable contributions to science publishing.

We apologize for the inadvertent breach of digital etiquette, but we really need to work collectively, to realize that we are together, to gain strength and energy. The point of departure for this editorial was the suggestion by a colleague: "Cadernos, you should do an Editorial on the surprising repercussions of your Happy Holidays message and the excitement among researchers, eager to resist together in 2020 ".

We thus begin 2020 with the joy of knowing that CSP remains steadfast in its principles and social commitments to Democracy, Collective Health, and the SUS in a context of crisis and enormous challenges for health and science. All this, thanks to the work by so many people! People committed to the mission of a journal to publish studies focused on improving the living and health conditions of populations. People who, among so many 
other activities, write, review, produce, publish, disseminate, and read the articles in CSP. As Editors-in-Chief we can only say, "Many thanks!"

\section{Contributors}

M. S. Carvalho, L. D. Lima, and C. M. Coeli contributed to the writing and approval of the final version.

\section{Additional informations}

ORCID: Marilia Sá Carvalho (0000-0002-95660284); Luciana Dias de Lima (0000-0002-06408387); Cláudia Medina Coeli (0000-0003-17573940).

\section{References}

1. Vieira-da-Silva LM, Novaes HMD, Travassos C, Lima LD. Articles on health policies and health services in Cadernos de Saúde Pública/Reports in Public Health. Cad Saúde Pública 2016; 32:e0032716.

2. Cook J. Countering climate science denial and communicating scientific consensus. http:// climatescience.oxfordre.com/view/10.1093/ acrefore/9780190228620.001.0001/acre fore-9780190228620-e-314 (accessed on 27/ Jan/2020).

3. Brownell SE, Price JV, Steinman L. Science communication to the general public: why we need to teach undergraduate and graduate students this skill as part of their formal scientific training. J Undergrad Neurosci Educ 2013; 12:E6-10.

4. National Academies of Sciences, Engineering, and Medicine. Communicating science effectively: a research agenda. Washington DC: $\mathrm{Na}-$ tional Academies Press; 2017. 